\title{
Immunological memory: What's in a name?
}

\section{Thomas Pradeu${ }^{1}$ and Louis Du Pasquier ${ }^{2}$}

1. ImmunoConcept, CNRS \& University of Bordeaux, France.

2. Institute of Zoology, University of Basel, Switzerland.

Immunological Reviews, special issue on immunological memory, edited by Dirk Homann and Ross Kedl

Corresponding author:

Thomas Pradeu

ImmunoConcept, UMR5164

University of Bordeaux

146 rue Léo Saignat

33076 Bordeaux

France

Tel: +33 (0) 557579246

Fax: +33(0) 557571472

Email: thomas.pradeu@u-bordeaux.fr

\section{Acknowledgments}

We thank Isabelle Chrétien for the art work of Figure 1. T.P. has received funding from the European Research Council (ERC) under the European Union's Horizon 2020 research and innovation programme - grant agreement $n^{\circ} 637647$ - IDEM. 


\section{Immunological memory: What's in a name?}

\section{Summary (200 words):}

Immunological memory is one of the core topics of contemporary immunology. Yet there are many discussions about what this concept precisely means, which components of the immune system display it, and in which phyla it exists. Recent years have seen the multiplication of claims that immunological memory can be found in "innate" immune cells and in many phyla beyond vertebrates (including invertebrates, plants, but also bacteria and archaea), as well as the multiplication of concepts to account for these phenomena, such as "innate immune memory" or "trained immunity". The aim of this critical review is to analyze these recent claims and concepts, and to distinguish ideas that have often been misleadingly associated, such as memory, adaptive immunity, and specificity. We argue that immunological memory is a gradual and multidimensional phenomenon, irreducible to any simple dichotomy, and we show why adopting this new view matters from an experimental and therapeutic point of view.

\section{Keywords (3-6):}

Evolution; priming; trained immunity; somatic recombination; innate immunity; lymphocytes 


\section{Introduction}

There is no doubt that immunological memory is one of the central concepts of contemporary immunology (1). In fact, the very notions of "immunity" and "immunization" are directly related to the idea of immunological memory. Immunological memory has been traditionally understood as a long-term acquired protection, either through infection or vaccination (2-4). Later, immunological memory came to have a more specific meaning, namely the capacity to mount a quicker and more efficient immune response when a given antigen is met a second time (1).

Despite the centrality of the notion of immunological memory, there are many uncertainties about what it means, and in which components of the immune system as well as in which phyla it can be found. Until recently, the dogma of contemporary immunology was that only jawed vertebrates, using somatic rearrangement and clonal expansion of lymphocytes, displayed immunological memory - though with considerable variations according to classes (5). Yet recent years have witnessed two key extensions of the concept of immunological memory: a "cellular" extension and a "taxonomic" extension. The cellular extension describes the fact that immunological memory, long thought as a phenomenon limited to the lymphocytic compartment of vertebrates $(6,7)$, is now said to exist in various types of "innate" or "innatelike" immune cells (such as NK cells $(8-10)$, gammadelta T cells $(11,12)$, macrophages, monocytes (13), etc.) in vertebrates. The taxonomic extension relates to the abundance of claims about the existence of an immunological memory in invertebrates (14-16), plants (17, 18), and even in bacteria and archaea (19), where the term "memory" is generally used, in fact, in the first above sense (namely, acquired protection). For some, the cellular and the taxonomic extensions have together led to a "paradigm shift" $(20,21)$, as immunological memory can no longer be equated with the traditional concept of immunological memory, limited to $\mathrm{B}$ and $\mathrm{T}$ lymphocytes, and based on somatic recombination and clonal expansion.

Following these two extensions, the notion of immunological memory is now used in many different, heterogeneous, senses. For example, scientists have talked about immunological memory to describe phenomena having very different durations, from a few days in some invertebrates (e.g., (15)) to several decades or even the entire life in the mammalian immune system (e.g., (22)). Furthermore, immunological memory is sometimes understood as a phenomenon consisting in two responses (that is, a first effector immune response, then extinguished, and then followed by a second, stronger, effector immune response), while in other cases it is a phenomenon consisting in a single, persisting, response, potentially modified by boosts (23). In parallel, novel terms have been suggested to account for recently described phenomena, such as "innate immune memory" $(20)$ or "trained immunity" $(24,25)$. Given this multiplication of words, concepts, and meanings, one may wonder whether the notion of immunological memory is sufficiently unified and well-defined to remain scientifically fruitful.

The chief aim of this critical conceptual review is to explore and compare the different meanings of the notion of immunological memory, and to try to determine whether the concept should be divided into several distinct and well-defined dimensions. We show that there has too often been a confusion between the phenomenon of immunological memory (i.e., the fact that a stronger immune response occurs) and its underlying mechanisms (i.e., the pathways through which this stronger immune response is realized). This confusion has created problematic "mindsets", by which for example the search for similar mechanisms across phyla has hindered the recognition of similar phenomena. Moreover, we argue that many notions that have been conflated must be distinguished, particularly "adaptive immunity", "memory", and 
"specificity". We propose that immunological memory is "multiply realizable", which means that it can be achieved through extremely different mechanisms (26). Immunological memory is a gradual and multidimensional phenomenon, and therefore cannot be captured by any dichotomy. One important consequence of these claims is that, in our view, both the old dogma (i.e., only vertebrates possess immunological memory) and its critique (i.e., immunological memory is found almost ubiquitously across immune systems) are problematic, and only a thorough conceptual analysis will lay the foundation for a rigorous assessment of the extension of the phenomenon of immunological memory.

\section{Immunological memory: A short history}

The general idea underlying the concept of immunological memory is ancient. It refers to the very broad thought that the body exposed to a pathogen can acquire a long-term protection against that particular pathogen. This idea can be traced back to Antiquity. Later, vaccination was developed on the basis of this same concept. The procedure of "inoculation" of a benign form of smallpox has existed for a very long time, at least since tenth century China, and perhaps as early as Antiquity (27). This was later called "variolation", after Edward Jenner's work at the end of the $18^{\text {th }}$ century (28). More generally, modern vaccination, as developed by Pasteur, Koch, and many others, also rests on the very broad idea that the body can acquire a specific protection against a pathogen, and therefore become "immune" to its effects.

Despite the fact that the underlying idea of acquired protection is very old, the notion of "immunological memory" (sometimes "immune" or "immunologic" memory) as such is much more recent. It became widely used in the scientific literature in the $1950 \mathrm{~s}$ and $1960 \mathrm{~s}(29,30$, 30). Immunological memory is initially a metaphor, given that the capacity to remember is cognitive in nature. Some immunologists, especially Nobel laureate Niels Jerne, have gone quite far in the endowment of the immune system with cognitive-like capacities (31-33), but most immunologists seem to favor a more restrictive and mechanistic understanding of the notion of immunological memory. As immunologists of the 1950s and 1960s understood it, immunological memory was mechanistically a product of the activities of $\mathrm{B}$ and $\mathrm{T}$ lymphocytes, with a major role played by antibodies (34).

Until recently, the dogma of contemporary immunology was that only jawed vertebrates, using somatic rearrangement and most importantly clonal proliferation of lymphocytes, displayed immunological memory $(5,24)$. Surprisingly, this dogma neglected many experimental results showing the existence of different forms of "immunological memory" in invertebrates and even in plants (see below). Moreover, recent years have shown that memory cells of adaptive systems were much more diverse than expected (35). There are, for example, at least three subsets of memory T cells: central memory (TCM), effector memory (TEM), and tissue-resident memory (TRM) $\mathrm{T}$ cells $(36,37)$. Immunological memory is therefore much more complex and heterogeneous than usually thought, but despite these very important qualifications, the idea that immunological memory was limited to vertebrates displaying somatic recombination and clonal proliferation long remained dominant. However, the last two decades have witnessed an increasing recognition of two major extensions in the scope of immunological memory - one cellular, the other taxonomic - leading to what can be called an "extended view" of immunological memory.

\section{First extension of the notion of immunological memory: Which cells?}


Immunological memory, long thought as a phenomenon limited to $\mathrm{B}$ and $\mathrm{T}$ lymphocytes and based on somatic recombination and clonal proliferation $(6,7)$, is now said to exist in a large variety of immune cells, including natural killer (NK) cells, macrophages, and monocytes. This section examines how this extension occurred, and on which molecular mechanisms these alternative modalities of immunological memory are based.

One important source of confusion comes from the frequent but inappropriate association between "adaptive" immunity and immunological memory on the one hand, and "innate" immunity and absence of immunological memory on the other (e.g., $(1,25,38))$. All these terms are the result of a long and chaotic history, which has led to numerous ambiguities (39-43). A reasonable attitude is to define "innate" immunity as germline-encoded, and "adaptive" immunity as based on somatic recombination and other somatic adaptations (43). With such a definition, components of the innate immune system can perfectly mediate immunological memory in the sense of a stronger and quicker response upon secondary stimulation (1). Another source of confusion concerns the different uses of the notion of "specificity": biochemical specificity (in terms of receptor-ligand interactions) should not be confused with target-specificity (e.g., the recognition of a single pathogen, or a family of pathogens with a very limited distribution).

A key step in the cellular extension of immunological memory concerns NK cells. NK cells are usually considered as innate lymphocytes (their receptors are germ-line encoded), activated by a complex balance of activating and inhibitory signals, with an important role in immune responses against infected, transformed, or allogenic cells. Recently, many authors have proposed that NK cells are capable of immunological memory $(9,38,44-47)$. Sensitization with haptens of mice lacking $\mathrm{T}$ and $\mathrm{B}$ cells leads to the generation of hapten-specific memory NK cells (48). The recall response persists for more than 4 months after priming, and can be adoptively transferred to naïve mice (49). Recently, it was shown that the NLRP3 inflammasome is a critical proinflammatory checkpoint in the induction of hapten-dependent memory NK cell (50). Moreover, NK cells can exhibit a memory specific to a given virus, such as mouse cytomegalovirus (MCMV). Virus-specific memory NK cells are also found in nonhuman primates $(51)$ and humans $(52,53)$. Crucially, NK cells that respond to MCMV undergo all four phases of the classical $\mathrm{T}$ or $\mathrm{B}$ cell response to a pathogen, namely expansion, contraction, memory maintenance, and recall (secondary response) (38). NK cell memory can also be induced by an inflammatory cytokine milieu (typically IL-12, IL-15, and IL-18), in the absence of a defined antigen, for up to 4 months $(54,55)$. Overall, NK cells can exhibit antigenspecific and relatively long-lasting memory (46) and, from a functional viewpoint, secondary NK responses upon re-stimulation are stronger than primary responses, both quantitatively and qualitatively (though they might be similar to primary responses kinetically).

Some features of immunological memory are also found in macrophages. Early studies showed that macrophages could be plastic and "adaptive": they can alter expression of pattern recognition receptors, leading to increased recognition of a broad spectrum of pathogens, enhancement of effector functions, and altered regulation of the inflammatory response (56, 57). Additionally, it was shown that macrophages could be primed by LPS and rendered more or less responsive to subsequent activation signals (58).

A set of recent and mechanistically very interesting studies have shown that monocytes and macrophages exposed to $C$. albicans or $\beta$-glucans exhibited an enhanced response to subsequent stimulation with unrelated pathogens or pathogen-associated molecular patterns 
(PAMPs), and that this enhanced response was mediated by epigenetic reprogramming $(13,59)$. Very recently, a series of five studies has shown that trained immunity could operate by both myeloid skewing of the hematopoietic compartment and cell-intrinsic changes (with a role for glycolysis, mevalonate synthesis, and mTOR activation) $((60,61)$; reviewed in $(62))$. Netea and colleagues see in these studies a confirmation of the concept of "trained immunity", which they had suggested in 2011, inspired by studies done in plants, invertebrates, and NK cells in vertebrates (24). They oppose trained immunity to "classical immunological memory" on the ground that trained immunity involves distinct cells and molecules, is nonspecific, is based on epigenetic reprogramming, and lasts weeks to months rather than years (63).

Other cells in which immunological memory exists include gammadelta $\mathrm{T}$ cells $(11,12)$, and innate lymphoid cells (64). Given all these data, the restriction of the phenomenon of immunological memory to B or T cell-mediated adaptive immunity must clearly be rejected (63), as at least some hallmarks of immunological memory exist in so-called "innate" immune cells.

\section{Second extension of the notion of immunological memory: Which phyla?}

The second currently discussed extension of the notion of immunological memory is taxonomic. Indeed, there has been in recent years a growing recognition that immunological memory, traditionally conceived as limited to vertebrates, was actually found across phyla, including in invertebrates, plants, and even bacteria and archaea. As a matter of fact, the longdominant idea that immunological memory is found only in vertebrates endowed with $\mathrm{B}$ and $\mathrm{T}$ lymphocytes neglected the numerous experimental results showing the existence of different forms of immunological memory in invertebrates and plants. In this section, we first review the evidence that has been accumulated during the $20^{\text {th }}$ century about immunological memory in invertebrates and plants, before turning to claims made since the 2000s about supposedly ground-breaking discoveries on invertebrate immunological memory.

In invertebrates, there have been attempts since at least the 1960s to assess the existence of an immunological memory in the context of transplantation. In the early 1960 s, the Nobel prize awarded to Burnet and Medawar for the discovery of immunological tolerance in mammals (essentially based on skin transplantation studies) raised the attention of some zoologists to the immunological nature of graft rejection, which could show specificity and memory. They wondered whether this immunological nature of graft rejection was a general phenomenon, i.e., whether it could also be demonstrated in vertebrates other than warm blooded animals and perhaps even in invertebrates. Therefore, many zoologists investigated specific memory in cold-blooded vertebrates and invertebrates in the context of graft rejection (65). The protocols were borrowed directly from mammalian studies:

(i) Application of a skin graft, or body wall segment, followed by observation of acceptance or rejection.

(ii) After complete rejection of the first graft, application of a second graft from the same donor to the same host, in parallel with a graft from a third-party, genetically unrelated, donor as a control. If memory was present, then the second graft from the same donor was rejected faster than the first. If specific memory was present, then the third-party graft was rejected like the first one, and not like the second one. 
Most of the early papers on this topic found specificity and memory in graft rejection, mainly done at this early time in earthworms (Table 1). But these results were deeply biased by the mindset installed by studies made in warm blooded vertebrates, and most of them suffered from imperfect controls.

\begin{tabular}{|c|c|c|c|c|c|c|c|}
\hline \multirow{2}{*}{$\begin{array}{l}\text { Phylum or } \\
\text { Class }\end{array}$} & \multirow[t]{2}{*}{ Host species } & \multirow{2}{*}{$\begin{array}{l}\text { Graft } \\
\text { type } \\
\text { Allo or } \\
\text { Xeno }\end{array}$} & \multicolumn{3}{|c|}{ Rejection time in days } & \multirow[t]{2}{*}{ Claim } & \multirow[t]{2}{*}{ Refs } \\
\hline & & & First set & $\begin{array}{l}\text { Second } \\
\text { set } \\
\text { (third } \\
\text { set) }\end{array}$ & $\begin{array}{l}\text { Third } \\
\text { party }\end{array}$ & & \\
\hline Porifera & $\begin{array}{l}\text { Callyspongia } \\
\text { Hymeniacidon } \\
\text { Ephydatia } \\
\text { Axinella } \\
\end{array}$ & $\begin{array}{l}\text { Allo } \\
\text { Allo } \\
\text { Allo } \\
\text { Allo } \\
\end{array}$ & $\begin{array}{l}7-11 \\
5-11\end{array}$ & $\begin{array}{l}3.8-7.2 \\
7.9-8.0\end{array}$ & $\begin{array}{l}4.6- \\
6.8 \\
5.4- \\
12.25 \\
\end{array}$ & $\begin{array}{l}\text { Specific short-term } \\
\text { memory } \\
\text { No memory } \\
\text { No memory } \\
\text { No memory } \\
\end{array}$ & $\begin{array}{l}(66) \\
(67), \\
(68)\end{array}$ \\
\hline Cnidaria & $\begin{array}{l}\text { Montipora } \\
\text { Eunicella } \\
\text { Anthopleura }\end{array}$ & $\begin{array}{l}\text { Allo } \\
\text { Allo, } \\
\text { Xeno } \\
\text { Allo }\end{array}$ & $\begin{array}{l}19.2- \\
25.3\end{array}$ & $\begin{array}{l}11.6- \\
14.4\end{array}$ & $\begin{array}{l}18.4- \\
28.5\end{array}$ & $\begin{array}{l}\text { Specific memory } \\
\text { No memory in vitro } \\
\text { killing assays } \\
\text { No memory }\end{array}$ & $\begin{array}{l}(69) \\
(70) \\
(71)\end{array}$ \\
\hline Nemertea & Lineus & Xeno & $14-16$ & $6.8-9.8$ & $\begin{array}{l}12.3- \\
18.0\end{array}$ & Specific memory & (72) \\
\hline Annelida & $\begin{array}{l}\text { Lumbricus } \\
\text { Eisenia }\end{array}$ & $\begin{array}{l}\text { Allo } \\
\text { Allo } \\
\text { Xeno }\end{array}$ & $7-60$ & $4-32$ & $5-81$ & $\begin{array}{l}\text { Accelerated rejection, } \\
\text { weak specificity, and } \\
\text { short-term memory } \\
\text { Conflicting results } \\
\text { Conflicting results }\end{array}$ & $\begin{array}{l}(73) \\
\\
(74- \\
76)\end{array}$ \\
\hline Arthropoda & Periplaneta & $\begin{array}{l}\text { Allo } \\
\text { Allo } \\
\text { Xeno }\end{array}$ & 7 & $3-5$ & 7 & $\begin{array}{l}\text { Specific memory } \\
\text { (hemocyte transfer) } \\
\text { No rejection } \\
\text { Non-specific priming } \\
\text { (cuticle transfer) } \\
\end{array}$ & $\begin{array}{l}(77 \\
78)\end{array}$ \\
\hline Mollusca & Biomphalaria & $\begin{array}{l}\text { Allo, } \\
\text { Xeno }\end{array}$ & & & & Hardly any rejection & (79) \\
\hline Echinodernata & $\begin{array}{l}\text { Dermasterias } \\
\text { Lytechinus }\end{array}$ & $\begin{array}{l}\text { Allo } \\
\text { Allo } \\
\end{array}$ & $\begin{array}{l}213 \\
38 \\
\end{array}$ & $\begin{array}{l}44.2 \\
(8.0) \\
12 \\
\end{array}$ & $\begin{array}{l}300 \\
(47) \\
12 \\
\end{array}$ & $\begin{array}{l}\text { Specific memory } \\
\text { Memory without } \\
\text { specificity }\end{array}$ & $\begin{array}{l}(80) \\
(81)\end{array}$ \\
\hline Tunicata & $\begin{array}{l}\text { Styela } \\
\text { Botryllus }\end{array}$ & $\begin{array}{l}\text { Allo } \\
\text { Allo }\end{array}$ & $\begin{array}{l}38.2 \\
13-53\end{array}$ & $\begin{array}{l}22.0 \\
7-62\end{array}$ & $\begin{array}{l}30.0 \\
\text { ND }\end{array}$ & $\begin{array}{l}\text { Specific memory } \\
\text { No memory }\end{array}$ & $\begin{array}{l}(82) \\
(83)\end{array}$ \\
\hline Agnatha & Eptatretus & Allo & 71.9 & 28.0 & $19-85$ & Specific memory & $(84)$ \\
\hline Gnathostomata & Xenopus & Allo & 30.9 & 18.6 & 35.0 & Specific memory & $(85)$ \\
\hline
\end{tabular}

Table 1. Immunological memory in transplantation experiments in invertebrates and vertebrates

Whereas demonstration of specific memory was easily obtained for reptiles, amphibians, and fish, doubts were raised in invertebrates when many experiments could not be confirmed, or were not done with the appropriate controls (Table 1). The generalization to all phyla and classes of the notion of specific immunological memory was therefore problematic and if allorecognition was demonstrated throughout phyla, specificity and memory in the vertebrate sense were not. Some cases remained suggestive of their existence, but with some uncertainty about specificity (in echinoderms and nemerteans, for instance).

In jawless vertebrates such as the lamprey and hagfish an important discovery was that of a variation on the theme of clonal selection, thanks to a new type of somatically generated variable lymphocyte receptor system, based neither on immunoglobulin superfamily nor on recombination-activating genes (RAG) (86). In this system, cytidine deaminases, AID -like 
enzymes generate somatically, in the agnathan lymphocytes, a highly diversified repertoire of Leucine rich repeats receptors.

In invertebrates, innate immunity is due to variation in the regulation of transcription of immunity-related genes, not to clonal proliferation of effector cells. Vertebrate immunological memory being based on clonal proliferation, it was easy to conclude, prematurely perhaps, that memory did not exist in invertebrates. In fact, what was shown was only that the type of immunological memory based on clonal proliferation did not exist in invertebrates. But this did not mean that they could not display other types of immunological memory. In fact, there are many reasons to moderate this highly restrictive conception of immunological memory based on clonal proliferation. For example, it has been demonstrated that there exists a population of long lived plasma cells responsible for a different form of memory in mammals (87), and analogous situations could certainly be encountered in invertebrates.

One important problem when considering immunological memory in invertebrates brings us back to the very meaning of the word "memory". In many cases, the data are compatible with acquired protection due to an ongoing response rather than an anamnestic response implicating the reactivation of "memory cells" (discussed below).

More recently, the quest for immunological memory has been extended to many antigenic challenges in a diversity of invertebrate phyla (reviewed in $(5,14)$ ). In particular, ecologists and evolutionary biologists interested in immune systems have investigated immunological memory in invertebrates, not anymore in a transplantation context, but this time in an infectious context. Unfortunately, this created much confusion, as the terminologies used by ecoimmunologists and traditional immunologists were quite different. The former tended to consider the immune system as a black box and were interested essentially in the relationships between inputs and outputs on each side of the box. The latter aimed at understanding the mechanistic cascade of events happening within that black box. For example, the crucial notion of "priming" was understood in very different ways by these two communities.

In many cases, the description of invertebrate immunological "memory" in an infectious context remains mostly phenomenological, and a precise knowledge of the underlying mechanisms is often lacking, which has paved the way for controversies (88-90). Importantly, some forms of immunological "memory" in invertebrates are very short, i.e., they last only a few days (e.g., (15)), while others are much longer.

A recent review (14) gives a comprehensive overview of the experiments done across all phyla, from which Figure 1 has been derived, after addition of supplementary references. That review presents cases where memory was investigated, but not always firmly proven (for instance see below the case of Dscam) because certain the experiments were never confirmed or never repeated, and some conflicting results remain.

One thing that is sure is that responses of invertebrate innate systems, whether to pathogens or grafts, are very complex and intricate (e.g., (91)), the antigen used for experiments being in general extremely complex assemblies of molecules (bacteria, viruses, helminths), and not a single hapten (like is often the case in vertebrate models). Examples of memory in invertebrates are in general fitting well rather with the establishment of protection than with the intervention of memory cells being reactivated. So far, this is perhaps simply due to the protocols chosen, which most of the time involved a very short period of time between the first encounter with 
the antigen and the challenge, together with a lack of determination of the end point of a primary response.

When investigating immunological memory in invertebrates and comparing it with vertebrates, it is also crucial to keep in mind that classical vertebrate T-B immunological memory can show enormous variation from one class of animals to the other (see also below the section "Immunological memory as a multidimensional and gradual concept"). If mammals, anuran amphibians, and birds show specific memory in a variety of experimental conditions, the same is not true for urodele amphibians, cartilaginous or bony fish (reviewed in $(92,93)$ ), where memory can be very difficult to observe (except in graft rejection experiments). Considerable variability can also be encountered within classes - for instance in teleost fish where memory is almost impossible to observe in some species such as the cod (92). Many features of antigenspecific responses in cold blooded vertebrates are different from what is known in homeotherms. This, for example, has considerably impaired the vaccination program in aquaculture. In some cases variation in the constitutive genes of the immune system might be considered responsible (for instance the lack of class II in various teleost species (reviewed in (5))), but in many other cases the reasons are unknown, except that, as a rule, the fish lymphoid organs lack germinal centers, a structure very important for the selection of mutants and hence a priori for the generation of memory (94).

Immunological memory has been particularly well studied in insects at several levels. Priming Drosophila with a sublethal dose of Streptococcus pneumoniae protects against a second challenge of $S$. pneumoniae that would otherwise be lethal, and this microbe-specific protection persists for the entire life of the fly (95). A similar specific protection can be elicited by Beauveria bassiana, a natural fly pathogen, but not all microbes could trigger such specific responses (95). An interesting study found immunological memory in the Anopheles gambiae mosquito, the major vector of Plasmodium falciparum malaria in Africa (96). Invasion of the mosquito midgut by Plasmodium ookinetes in the presence of gut bacteria primed a long-lived enhanced antibacterial response that indirectly reduced the survival of Plasmodium parasites upon rechallenge. The priming led to a systemic enhanced immune surveillance. The proportion of circulating granulocytes increased, and changes in the morphology and binding properties of these cells were triggered. The priming was strong and persisted for the lifespan of the mosquito. Very recently, following work showing RNA interference spreading in Drosophila and its role in antiviral immunity (97), Tassetto and colleagues described a new mechanism of RNA interference amplification and dissemination (98). They showed that Drosophila haemocytes could amplify small interfering RNAs from non-germline-encoded DNA, package them, and send them to distal sites - a mechanism that provides protection to naïve cells. The protection is long-lasting and pathogen-specific, suggesting a parallel with mammal adaptive immunity (99). In various insects (and other arthropods as well) a cell surface receptor, member of the immunoglobulin superfamily, homologous to the human Down syndrome cell adhesion molecule, Dscam 1, is diversified by mutually exclusive alternative splicing and has been proposed as a possible PRR, playing a role in immunity and hence in immunological memory. However, the situation is far from being clear, many experiments failing to confirm its function as a pattern recognition receptor (100). Moreover, different forms of immune "priming" have been described in insects, though most of the time the protective effect is not very long and it results from a persisting response rather than a re-activation (101).

The phenomenon of "immunological memory" is discussed not only in vertebrates and invertebrates, but also in plants. In fact, the existence of this phenomenon was already described by Beauverie and Ray in 1901, and extensively discussed in the 1930s (102-104). Later, the 
mechanisms responsible for this phenomenon were explored in more detail (105). Plant immunological memory is based on "defense priming", that is, the fact that a plant primed by a stimulus mounts a faster and stronger defense (both in the exposed tissue and systemically) compared to an unprimed plant $(17,106,107)$. Defense priming is observed in the different types of immune responses found in plants, including systemic acquired resistance (SAR), induced systemic resistance (ISR), wound-induced resistance (WIR), and chemically-induced immunity (17). Systemic acquired resistance (SAR) is often described as a prominent form of immunological memory in plants (102). SAR refers to broad-spectrum immunity to reinfection throughout the whole organism $(17,18,108)$. It can last from a few days to the entire life of the plant, and can be inherited $(17,109)$. Mechanistically, plant immunological memory is mediated by several processes, including epigenetic ones, such as histone modification and DNA demethylation (110). Overall, plants display some characteristics of immunological memory, and homologies and analogies between plant and animal immunological memory are increasingly discussed (20).

Even more mind-blowing is the recent discovery that a form of immunological memory can be found in bacteria and archaea, within the CRISPR (Clustered, regularly interspaced, short palindromic repeats)-Cas system (19, 111-115). CRISPR-Cas systems confer bacteria and archaea with protection against phages and other mobile elements (including plasmids and transposons), through a three-step process $(114,116)$. In the first step (called "adaptation"), small fragments of DNA from the invader are incorporated into the CRISPR array of the host. In the second step ("expression and processing"), the CRISPR array is transcribed, and the precursor transcript is processed to generate CRISPR RNAs (crRNAs). During the third step ("interference"), the crRNA guides a complex of Cas proteins to the matching target, which initiates the destruction of the invading nucleic acid (114). The immunological memory associated with CRISPR-Cas systems occurs during the first step (adaptation). As new spacers derived from the genome of the invader are incorporated into the CRISPR array along with a new repeat unit, information about this invader is stored, and can be used to face subsequent invasions - a phenomenon sometimes referred to as "priming" $(111,113)$. In this case, the presence of spacers with a full or partial match to the invading nucleic acid increases the frequency of acquiring another spacer (113). The generation of a memory of past infections allows a more efficient reaction upon recurrent infections and allows the bacterial (or archaeal) population to rapidly mount a response upon re-exposure $(112,116)$. Thus, the CRISPR memory banks are regularly updated with novel invader-associated information (114), always at the level of a whole population, and not at the level of the individual bacteria or archaea. Finally, a crucial and distinctive feature of CRISPR-Cas-mediated immunological memory is that it is transmitted to the progeny after bacterial duplication (though some acquired spacers can be lost $)(114,116)$.

Overall, certain features traditionally associated with immunological memory are found in plants, invertebrates, and in innate cells of vertebrate immune systems, which substantiates the claim that immunological memory is much more extensive than previously thought. It also illustrates the fact that all immune systems face the selective pressure of microbial pathogens, and that for all of them it is crucial to be able to benefit from experience.

Some authors have suggested the term "innate immune memory" to account for immunological memory realized by constituents traditionally associated with the innate compartment of the immune system $(20,21)$. This term is nonetheless misleading in so far as something that results from the benefit of experience can hardly be called "innate". It seems more appropriate to simply extend the concept of immunological memory (so that it can include $\mathrm{T}$ and $\mathrm{B}$ 
lymphocytes, but also NK cells, monocytes, and other cells) rather than putting in parallel "immunological memory" on the one hand, and "innate immune memory" (or "trained immunity") on the other. As a matter of fact, the term "innate immune memory" could be better suited to describe another phenomenon, namely the repertoire that every organism in a given species receives from its ancestors, is germline-encoded, and reflects the history of its species with some microbes. This is what one can call the "phylogenetic memory", which corresponds to the role attributed by Janeway to antigen-presenting cells and their capacity to recognize pathogen associated molecular patterns (PAMPs) via pattern recognition receptors (PRRs) (117). This is probably an important phenomenon, though it has generally been neglected in discussions about immunological memory. For example, 50\% of NK cells in C57BL/6 mice are specific to the MCMV before infection (43).

\section{Multirealizability and "mindsets"}

The previous discussion illustrates the importance of distinguishing between the phenomenon of immunological memory and its underlying mechanisms. Even though that distinction might seem obvious from a present-day perspective, these two aspects have sometimes been confused, with detrimental consequences.

For example, to address the existence of immunological memory in invertebrates, several researchers, obsessed with the model of RAG-based immunity, tried to find in invertebrates an equivalent of this model. Such "mindsets" can sometimes hinder the process of scientific discovery (118), as has been documented in immunology (119). In the present case, two great advances made between the 1950s and the mid-1970s were the discovery that graft rejection was an immunologically specific reaction with memory, and the discovery of the somatic generation of antibody diversity in the adaptive immune system of gnathostome vertebrates. Together, these findings created mind-sets that slanted the approach toward understanding invertebrate immunity. It was logical to ask whether specific allograft rejection with memory and the "antibody model" (sensu lato) applied to all metazoans. But many scientists quickly veneered the invertebrates with models influenced by the vertebrate mindsets, after sometimes over-interpreting experiments that were not always performed rigorously and, in many cases, could not be reproduced. This lasted until molecular biology analyses failed to confirm the soft results that suggested the existence of specific adaptive response in invertebrates.

The distinction between the phenomenon of immunological memory and its underlying mechanisms provides the basis for the simple but important claim that immunological memory is "multiply realized". Memory seems to have so many advantages that it is not surprising to find it achieved in different domains with analogies but no homologies. It is so important a function that it cannot be devoted to a single system, but to complementary or alternative ones as fail-safes. Multiple realization is a classic concept in philosophy (26). It means nothing more than the fact that a given phenomenon or function can be achieved through extremely different pathways, something that frequently happens in biology (120). In our case, the phenomenon of immunological memory can perfectly be common to different taxa, and within taxa and individuals to different pathways, without being based on the same underlying mechanisms. Again, as obvious as this distinction might seem, its adoption in past immunology could have prevented hasty or even false interpretations. It seems equally crucial, in future research about immunological memory, to be very explicit about what exactly is under investigation - the phenomenon of immunological memory or one specific mechanism. 


\section{Immunological memory as a multidimensional and gradual concept}

The distinction between the phenomenon and the mechanisms of immunological memory must not hide the extensive heterogeneity of the phenomenon. What has been described as an "immunological memory" in the literature can vary extensively in terms of duration, rapidity, specificity, etc. We therefore suggest to define immunological memory as a multidimensional concept, and to assess these different dimensions separately. These distinctions between different dimensions of immunological memory are not for the sake of mere terminological consideration. Instead, saying in which sense one understands the notion of immunological memory is crucial to determine to what extent it can be applied to new cells and/or to new species, and to design rigorous experimental tests.

The five key dimensions of immunological memory are:

- Strength: this dimension measures the degree of increase in strength (both quantitative and qualitative) of the second immune response upon rechallenge, in comparison with the first immune response.

- Duration: this dimension measures how long the capacity for a stronger response upon rechallenge lasts.

- Speed: this dimension represents the degree of increase in rapidity of the second immune response upon rechallenge, in comparison with the first immune response.

- Specificity: this dimension shows whether the second response upon rechallenge is specific to a given target (e.g., a given pathogen), or on the contrary has a wide spectrum.

- Extinction: this dimension illustrates whether the stronger response upon rechallenge is due to the mere persistence of a unique, prolonged, immune response, or rather to true re-activation, that is, a first immune response followed by an extinction of the response, and then by a new activation. See Figure 2 for a simplified view of these two different situations.

These dimensions are all gradients. A phenomenon of immunological memory will be more or less strong, more or less durable, etc. Even extinction could be a matter of cell number rather than presence or absence of cells. This is why we propose to conceive immunological memory as both a multidimensional and gradual concept. To say that there is a continuum, as many authors do (e.g., (43)), is important but not sufficient, because there are in fact several distinct continuums, with only partial overlap. For example, the continuum of specificity (to the recognized target) does not strictly overlap with the continuum of duration, or with the possible continuum between innate (germline) and adaptive (somatic recombination-based) immunity. This confirms that identifying continuums is essential, but makes real sense only within a multidimensional approach to immunological memory. Moreover, and as stated above, another aspect of this gradation are the variations in the parameters of immunological memory that one sees among the members of a single class of metazoans, or among the classes within a phylum.

This multidimensional, gradual, and intricate approach helps us see why phenomena that have all been described as instances of "immunological memory" can actually be extremely different. (One clear example of intricacy is the fact that in human B cells TLRs are downstream of BCR and play a role both in the primary response and in the memory phase (121)). Figure 3 offers a highly oversimplified representation of the aforementioned differences. This figure distinguishes six situations (namely somatic recombination and clonal expansion; NK cell memory; epigenetic reprograming-based memory in monocytes and macrophages; invertebrate 
secondary response in an infectious setting; plant immunological memory; and CRISPR-Casbased immunological memory in bacteria and archaea), and it compares them along the five dimensions of immunological just described. This representation is necessarily oversimplified and even to some extent misleading, because it is impossible to establish a common system of measurement for phenomena that happen at different temporal scales and in organisms that exhibit radical differences in terms of lifespan, physiological organization, and many other features. Additionally, the experimental readouts often differ in the scientific literature - for example, it is sometimes the intensity of the response, while in other cases it is the survival of the infected hosts.

Despite these limitations, the figure is very useful to make a coarse-grained comparison between different phyla and cell types. Moreover, and most crucially, for the two key dimensions of strength and speed, our figure makes an "internal" comparison - that is, it compares the primary response (following first challenge) to the secondary response (following second challenge) within the same species in given experimental conditions. The aim of this figure is only to convey an idea of the main differences among phenomena all described as illustrations of the existence of an immunological memory, but which, again, can display quite distinct characteristics. Our take home message here is not that Figure 3 would represent faithfully the features of immunological memory in different settings, but rather - and crucially - that it is only by examining and measuring as precisely as possible all these dimensions that the immunological community will be able to draw rigorous and insightful conclusions.

Figure 3 helps emphasize important differences among phenomena that have often been put together under the label "immunological memory". For example, NK cell-based immunological memory (Fig. 3b) corresponds to a stronger, long-lasting, specific, and extinction-associated immune response, but it is unclear whether the response is faster. Immunological "memory" based on epigenetic reprograming in monocytes and macrophages (Fig. 3c) is undoubtedly an important phenomenon, but it is essential to keep in mind that duration and specificity are very limited, that there is no extinction. Acquired protection in invertebrates in an infectious context (Fig. 3d), such as the very frequently cited experiment in copepods (15), has a short duration, does not lead to a necessarily faster response, exhibits limited specificity, and does not display extinction. In plants (Fig. 3e), the response upon rechallenge is generally stronger and faster and it can be long-lasting, but it is most often unspecific, and there is no extinction. For a phenomenon like CRISPR-Cas-based immunological memory in bacteria and archaea (Fig. 3f), the figure confirms that it has much in common with the "classical" phenomenon of immunological memory traditionally associated with lymphocytes. Of course, all the dimensions that appear in this figure are simplifications: for example, even lymphocytes exhibit considerable cross-reactivity and degeneracy $(39,122)$, so their high score for "specificity" is no more than an approximation, because specificity will vary very significantly depending on the situation under consideration.

Importantly, "more" at the response level does not necessarily mean "better" at the organism level. Immunological memory can be very useful to protect a host against reinfection, but it can also have detrimental consequences in pathological contexts, including allergies (123), autoimmune diseases and aging (124), as well as graft rejection (125). Thus, the same features that seem to make of lymphocyte-based immunological memory the most "perfect" form of immunological memory can in fact prove to be particularly harmful in certain situations.

Figure 3 focuses on the description of immunological memory at a phenomenal, rather than mechanistic, level, but it can also offer an appropriate basis to investigate mechanisms in more 
detail. It is in fact crucial to relate the different (gradual) dimensions distinguished here to their underlying mechanisms. It is likely that some mechanisms will preferentially be associated with some features at the phenomenal level. For example, epigenetic reprogramming is probably associated with a relative short duration of immunological memory (in mammals, for example, it could be weeks or even months, but probably not years). Having a clear representation of the different dimensions of immunological memory at the phenomenal level is particularly useful to subsequently investigate the different mechanisms on which they are based, and what these mechanisms may have in common.

Since its inception, the term immunological memory has most frequently been understood through dichotomies, such as "innate" vs. "adaptive" immunity, "nonspecific" vs. "specific" immunity, and many others. As heuristically useful as these dichotomies might have been at certain steps in the past, it should be clear that they are unable to capture the phenomenon of immunological memory in all its diversity and richness. Even the recent concept of "trained immunity" is presented by its proponents on the basis of a dichotomy. They oppose trained immunity to "classical immunological memory": trained immunity, according to them, involves distinct cells and molecules, is nonspecific, based on epigenetic reprogramming, and lasts weeks to months rather than years. Accordingly, they see the memory characteristics of trained immunity as "fundamentally different" from the classical adaptive immunological memory (24). Yet this dichotomy is misleading because, here again, the phenomena under consideration are gradual, not binary. For example, NK cell memory can be specific, and epigenetic mechanisms probably also play a role in T and B lymphocytes. All these dichotomies create misleading mindsets, which strongly suggests that they should be abandoned in favor of the multidimensional and gradual view proposed here. Even if the term trained immunity was used as an overarching term, encompassing all forms of immunological memory, both "innate" and "adaptive", its utility would still be questionable because it would be redundant with the (extended) notion of immunological memory itself.

\section{Conclusion: What has changed in the concept of immunological memory, and why does it matter?}

Immunological memory is much more widespread and diverse than suggested by the dominant view over the last decades. This "extended view" about immunological memory is consistent with the fantastic extension of the domain of immunology: immune systems, for a long time studied thoroughly only in vertebrates, are now documented across all living things $(126,127)$. In our view, the extension of the concept of immunological memory is extremely important but, contrary to what has often been claimed, it does not constitute a "paradigm shift" in Thomas Kuhn's sense. A paradigm shift occurs when two radically different conceptual frameworks, based on distinct worldviews, come into competition, and one of them triumphs (118). This is not what happened with the concept of immunological memory. Rather than a paradigm shift, what occurred is what can be described as a "multiple opening": once very restricted, immunological memory is now recognized to be highly diverse - both in terms of mechanisms, and in terms of the different dimensions by which this phenomenon can be described and measured.

This is why we have suggested that the most fruitful way of dealing with immunological memory nowadays was to adopt a multidimensional and gradual conception of immunological memory. This conception exists implicitly in the scientific literature, but, to our knowledge, it has not been expressed in detail, and all its consequences have not been explored. The dominant 
approach, as we saw, remains to think about immunological memory in dichotomous terms, which in general is misleading.

Conceptual analysis of immunological memory matters for several reasons. First, the extension of the concept of immunological memory has important practical consequences. If immunological memory exists in some plants, invertebrates, and bacteria as well as archaea, then vaccination could be developed in these organisms. The impact on horticulture, livestock farming, or food industry are potentially colossal (128-131).

Moreover, examining the different processes of immunological memory makes good sense with regard to the increasingly acknowledged phenomenon of redundancy in the immune system $(132,133)$. Learning about the different manifestations of memory, one by one, could help in pathological cases, where one or the other fails. The remaining pathways, where memory can be stimulated, could perhaps be over-stimulated to compensate the failure of the defective system. It is well-established, for example, that mice devoid of T cells and B cells can develop an NK-based specific memory response, which suggests the possibility to exploit such a compensatory mechanism (134). That such compensations can occur is also illustrated by some "natural KO experiments" such as the absence of MHC class II and CD4 in the cod, which seems to be compensated by an expansion of the gene families encoding class I and TLRs (135). In the same way, the adaptive immune response and memory in many fish are rather inefficient, but they appear to be compensated by a well-developed complement system showing an expansion of the $\mathrm{C} 3$ component family (136).

Extending the notion of immunological memory also opens up very stimulating therapeutic approaches that are based on cross-species comparisons. For example, epigenetic reprogramming in plants inspired the investigation for potentially similar mechanisms in mammals, an approach that proved successful for monocytes, macrophages, and perhaps other cells, and which may lead to novel vaccination strategies (63). It is tempting to speculate that future studies will provide more examples of this kind, where seemingly "fundamental" research on immunological memory offers a very important basis for clinical applications. Finally, immunological memory is often seen from the viewpoint of the advantages it provides in an infectious context, but, as we saw, it can be detrimental in many pathological situations for example allergies (123), autoimmune diseases (124), and graft rejection (125). Exploring the different dimensions of immunological memory will be useful to understand these pathologies and better determine how to cure them. Of course, specificity and duration will be particularly crucial in that context.

Second, the multidimensional approach to immunological memory put forward in this paper paves the way for the construction of precise and rigorous guidelines for forthcoming experimental research. There is no doubt that scientists are investigating nowadays, and will continue to investigate in the near future, the existence of immunological memory in immune actors and/or phyla where they are currently not, or only partially, documented. This includes work done, for example, on gammadelta $\mathrm{T}$ cells and innate lymphoid cells in mammals, but also research on RNA interference and CRISPR-Cas associated "memory". Taking into account the multidimensionality of immunological memory will allow these researchers to establish much more explicitly which dimension(s) they aim to assess, and how (see Box 1).

- First, one should determine whether the investigation is about the existence of the phenomenon of immunological memory, or certain specific mechanisms already proved to mediate immunological memory in some contexts (e.g., somatic recombination, epigenetic reprogramming, RNA interference, etc.). 
- Second, because the phenomenon of immunological memory has multiple dimensions, one should clarify which one(s) of these dimensions are tested in a given experimental setting. Among these dimensions, five seem particularly important to assess, namely strength, duration (short-term vs. long-term memory), speed, specificity (specificity to the target), and extinction (via downregulation mechanisms).

- Third, memory could manifest itself at the recognition or the signaling levels. (Recognition can be in solution, at the cell surface level or inside the cell, and involve proteins or nucleic acids).

- Fourth, and despite many difficulties (see text), it is useful to compare the obtained results with other manifestations of immunological memory (other cell types in a given species; across species; etc.).

Box 1. Guidelines for immunologists willing to assess the existence and modalities of immunological memory in a given experimental setting. 


\section{Figures}

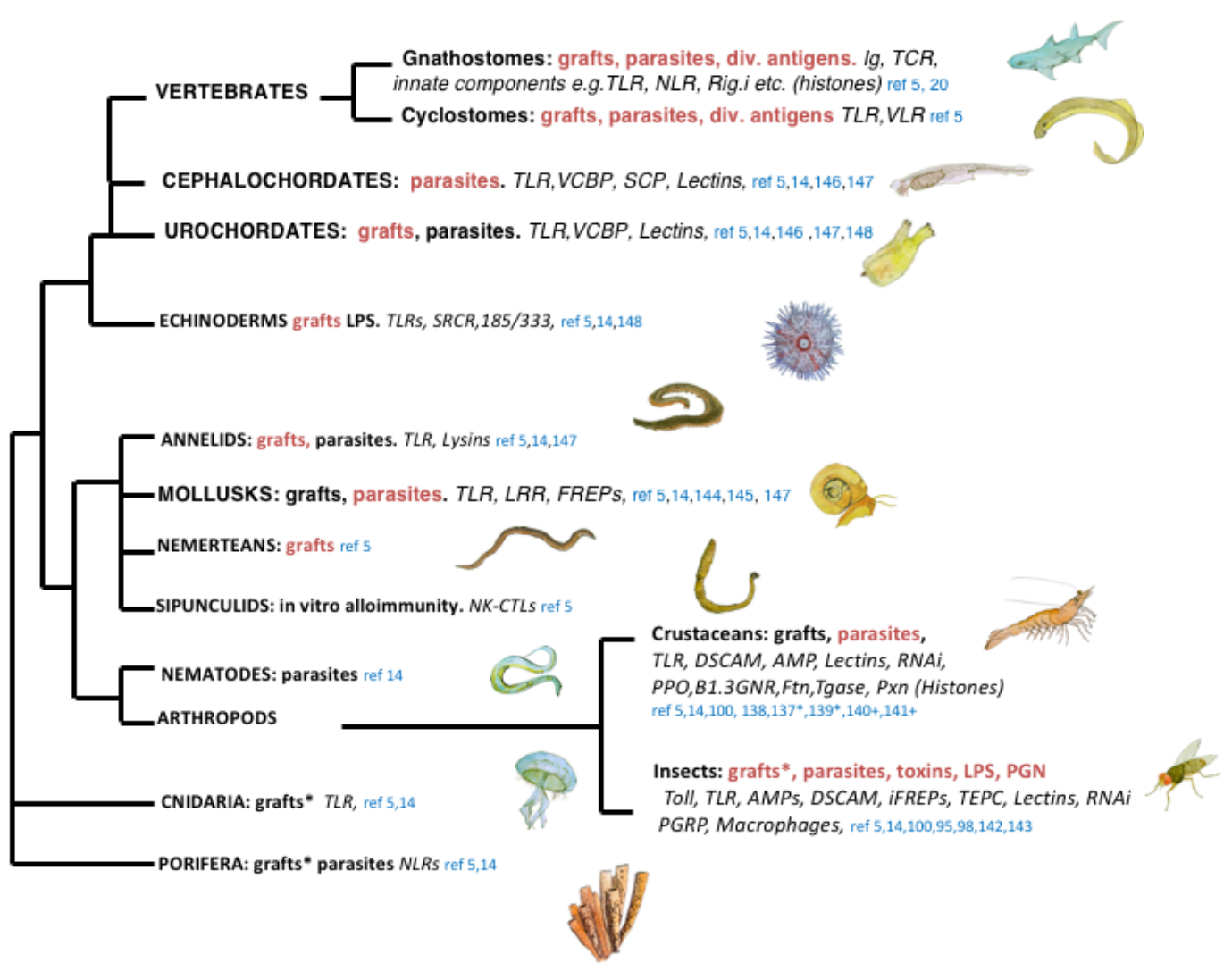

Fig.1. Immunological memory across the animal kingdom (After $(5,14))$.

Distribution among the various phyla of experiments done using grafts, parasites (virus, bacteria, protozoan and metazoan parasites) or antigens (LPS: lipopolysaccharide, PGN: Peptidoglycan, toxins) where a form of specific immunological memory sensu lato (i.e., including possibility of ongoing responses) has been investigated (all entries) and claimed (red). For details on grafts see Table 1.

In italics: putative effectors that can contribute directly or indirectly to protection.

Contribution of epigenetic factors has been found in ceustaceans (137) and in Vertebrates (20) (Histones) implies epigenetic reprogramming.

$*+$ : conflicting results

Abbreviations:

B1.3 GNR Beta 1.3 glucan receptor

FREP fibrinogen related receptors

Ig Immunoglobulins

LRR Leucin rich receptors

NK-CTL Natural killer cytotoxic leukocyte

NLR Nod like receptors

RIG1.1 Retinoic acid inducible gene I

SCP sarcoplasmic calcium binding protein

SRCR Scavenger receptor cystein rich

TCR T cell receptor

TLR Toll like receptors

VCBP Variable chitin binding protein

VLR variable leukocyte receptor 

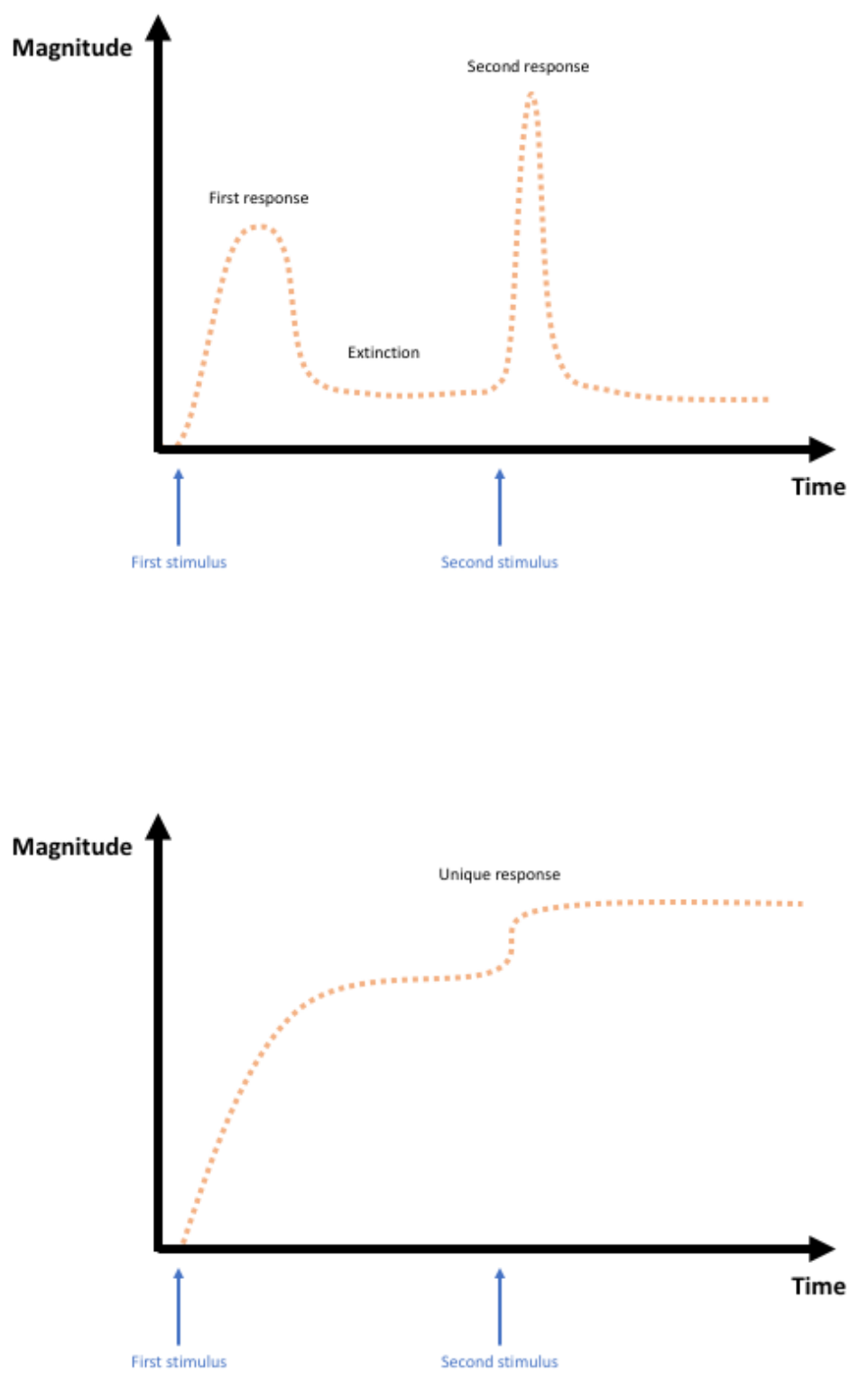

Fig. 2. Extinction in immunological memory.

One key aspect of the phenomenon of immunological memory is whether or not a first response is followed by an extinction phase, and then by a distinct second response. The upper panel (Fig. 2a) describes a situation where a first stimulus triggers a first response, followed by extinction, and then a second stimulus triggers a second, stronger, response. This is how immunological memory responses have traditionally been understood. The bottom panel (Fig. $2 b$ ) describes a situation where a stimulus triggers a unique response, not followed by an extinction phase. Many (but not all) studies presented as evidence for a form of immunological memory in plants and invertebrates correspond in fact to this second situation, where a unique and sustained immune response occurs, without extinction. 

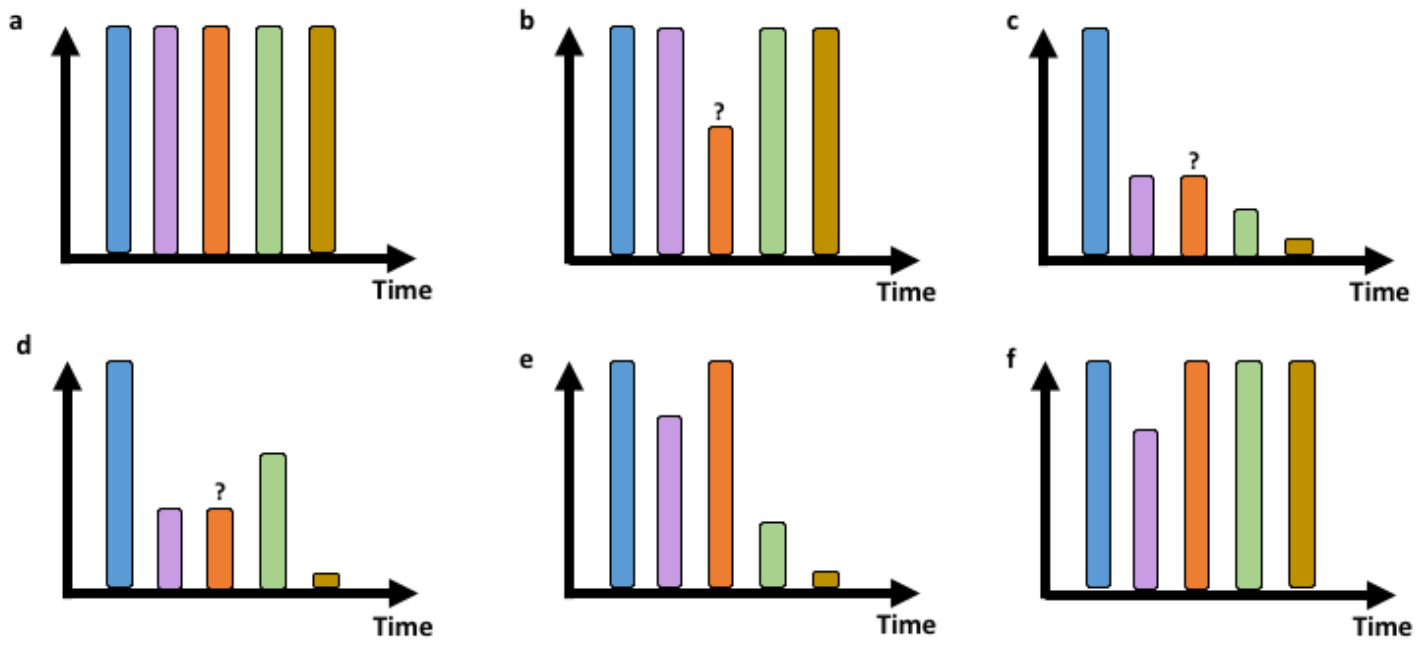

$\begin{array}{lcl}\text { Strength } & \text { Speed } \quad \text { Extinction } \\ \text { Duration } & \text { Specificity }\end{array}$

Figure 3: Comparison of different grades of immunological memory according to five key dimensions. The dimensions considered here are strength (is the second response stronger than the first?), duration (how long does the protective effect last?), speed (is the second response quicker than the first?), specificity (is the response specific to the target?), extinction (is the stronger response upon rechallenge due to the mere persistence of a unique, prolonged, immune response, or to true re-activation?). a. Immunological memory based on somatic recombination and clonal expansion in $B$ and $T$ lymphocytes in jawed vertebrates (could apply to jawless vertebrates as well). The five dimensions are all high, though situations vary (for example, specificity is much lower when there is cross-reactivity of B or T cell-receptors). b. NK-cell-based immunological memory. This type of immunological memory is very similar to that associated with B and $\mathrm{T}$ lymphocytes, though much uncertainty remains about whether the second response is quicker than the first (44). c. Immunological memory based on epigenetic reprogramming in monocytes and macrophages. The response upon rechallenge is stronger but often not quicker than what was observed with the first challenge; duration and specificity are very low, and in most cases there seems to be one single sustained response rather than a first response followed by an extinction and a second response (63). $\mathbf{d}$. Acquired protection in invertebrates in an infectious context (as exemplified in (15)). The response upon rechallenge is stronger but often not quicker than what was observed with the first challenge (or this latter aspect is unknown); duration is generally very low; specificity varies; there is one single sustained response rather than a first response followed by an extinction and a second response. e. Immunological memory in plants (typically SARassociated immunological memory). The response upon rechallenge is stronger and generally quicker than what was observed with the first challenge; several examples of long-term memory exist; specificity is low; there is one single sustained response rather than a first response followed by an extinction and a second response (17). f. CRISPR-Cas-based immunological memory in archaea and bacteria (113). The second response is stronger and quicker, and it is quite specific to the targeted phage (or other mobile element); the protection is long-lasting, but here duration is considered as the population level rather than the individual level; there seems to be an extinction of the response, though assessing this aspect in the present case is difficult. 


\section{References}

1. Farber, DL, Netea, MG, Radbruch, A, Rajewsky, K, Zinkernagel, RM.

Immunological memory: lessons from the past and a look to the future. Nat. Rev. Immunol. 2016; 16: 124-128.

2. Ahmed, R, Gray, D. Immunological memory and protective immunity: understanding their relation. Science 1996; 272: 54-60.

3. $\quad$ Editorial: Remembering things past. Nat. Immunol. 2011; 12: 461.

4. Zinkernagel, RM. On natural and artificial vaccinations. Annu. Rev. Immunol. 2003;

21: 515-546.

5. Flajnik, M.F. \& Du Pasquier, L. (2013). Evolution of the Immune system. Fundamental Immunology, 67-128.

6. Hull, CJ, Cheung, G, Okamoto, J, Akaka, L, Raison, RL, Hildemann, WH.

Immunological specificity and memory in a scleractinian coral. Nature 1977; 270: 219.

7. Rolf M. Zinkernagel, Martin F. Bachmann, Thomas M. Kündig, Stephan Oehen, Hanspeter Pirchet, Hengartner, and H. On Immunological Memory. Annu. Rev. Immunol. 1996; 14: 333-367.

8. Sun, JC, Beilke, JN, Lanier, LL. Adaptive immune features of natural killer cells. Nature 2009; 457: 557-561.

9. Sun, JC, Beilke, JN, Lanier, LL. Immune memory redefined: characterizing the longevity of natural killer cells. Immunol. Rev. 2010; 236: 83-94.

10. O'Sullivan, TE, Sun, JC, Lanier, LL. Natural Killer Cell Memory. Immunity 2015; 43: 634-645.

11. Sheridan, BS, Romagnoli, PA, Pham, Q-M, et al. $\gamma \delta$ T cells exhibit multifunctional and protective memory in intestinal tissues. Immunity 2013; 39: 184-195.

12. Ramírez-Valle, F, Gray, EE, Cyster, JG. Inflammation induces dermal V $\gamma 4+\gamma \delta T 17$ memory-like cells that travel to distant skin and accelerate secondary IL-17-driven responses. Proc. Natl. Acad. Sci. 2015; 112: 8046-8051.

13. Saeed, S, Quintin, J, Kerstens, HHD, et al. Epigenetic programming of monocyte-tomacrophage differentiation and trained innate immunity. Science 2014; 345: 1251086.

14. Milutinović, B, Kurtz, J. Immune memory in invertebrates. Semin. Immunol. 2016; 28: $328-342$.

15. Kurtz, J, Franz, K. Innate defence: evidence for memory in invertebrate immunity. Nature $2003 ;$ 425: 37-38.

16. Kurtz, J. Specific memory within innate immune systems. Trends Immunol. 2005;

26: $186-192$.

17. Reimer-Michalski, E-M, Conrath, U. Innate immune memory in plants. Semin. Immunol. 2016; 28: 319-327.

18. Spoel, SH, Dong, X. How do plants achieve immunity? Defence without specialized immune cells. Nat. Rev. Immunol. 2012; 12: 89-100.

19. Nuñez, JK, Bai, L, Harrington, LB, Hinder, TL, Doudna, JA. CRISPR

Immunological Memory Requires a Host Factor for Specificity. Mol. Cell 2016; 62: 824-833.

20. Quintin, J, Cheng, S-C, Meer, JW van der, Netea, MG. Innate immune memory:

towards a better understanding of host defense mechanisms. Curr. Opin. Immunol. 2014; 29: $1-7$.

21. Netea, MG, Latz, E, Mills, KHG, O’Neill, LAJ. Innate immune memory: a paradigm shift in understanding host defense. Nat. Immunol. 2015; 16: 675-679.

22. Banatvala, J, Van Damme, P, Oehen, S. Lifelong protection against hepatitis B: the role of vaccine immunogenicity in immune memory. Vaccine 2000; 19: 877-885.

23. Grotty, S., Kaech, S.M., \& Schoenberger, S.P. (2013). Immunological Memory. 
Fundamental Immunology, 741-764.

24. Netea, MG, Quintin, J, van der Meer, JWM. Trained Immunity: A Memory for Innate Host Defense. Cell Host Microbe 2011; 9: 355-361.

25. Netea, MG, Meer, JWM van der. Trained Immunity: An Ancient Way of Remembering. Cell Host Microbe 2017; 21: 297-300.

26. Shapiro, LA. Multiple Realizations. J. Philos. 2000; 97: 635-654.

27. Bazin, H. Vaccination: a history from Lady Montagu to genetic engineering. Montrouge:

J. Libbey Eurotext, 2011.

28. Plotkin, SA, Plotkin, SL. The development of vaccines: how the past led to the future. Nat. Rev. Microbiol. 2011; 9: 889.

29. Burnet, FM. Immunological recognition of self. Nobel Lect. Physiol. Med. 1960; 3: 689-701.

30. Uhr, JW, Finkelstein, MS. Antibody formation. IV. Formation of rapidly and slowly sedimenting antibodies and immunological memory to bacteriophage phi-X 174. J. Exp. Med. 1963; 117: 457-477.

31. Jerne, N.K. (1966). Antibody formation and immunological memory. Macromolecules and Behavior, 151-157.

32. Jerne, NK. The generative grammar of the immune system. EMBO J. 1985; 4: 847852.

33. Cohen, IR. Tending Adam's Garden: Evolving the Cognitive Immune Self. San Diego: Academic Press, 2000.

34. Uhr, JW. The Heterogeneity of the Immune Response. Science 1964; 145: 457-464.

35. Mueller, SN. Grand Challenges in Immunological Memory. Front. Immunol. 2017;

8:

36. Mueller, SN, Gebhardt, T, Carbone, FR, Heath, WR. Memory T cell subsets, migration patterns, and tissue residence. Annu. Rev. Immunol. 2013; 31: 137-161.

37. Mueller, SN, Mackay, LK. Tissue-resident memory T cells: local specialists in immune defence. Nat. Rev. Immunol. 2016; 16: 79-89.

38. Sun, JC, Beilke, JN, Lanier, LL. Adaptive immune features of natural killer cells. Nature 2009; 457: 557.

39. Vivier, E, Malissen, B. Innate and adaptive immunity: specificities and signaling hierarchies revisited. Nat Immunol 2005; 6: 17-21.

40. Vivier, E, Raulet, DH, Moretta, A, et al. Innate or Adaptive Immunity? The Example of Natural Killer Cells. Science 2011; 331: 44-49.

41. Flajnik, MF, Du Pasquier, L. Evolution of innate and adaptive immunity: can we draw a line? Trends Immunol. 2004; 25: 640-644.

42. Kvell, K, Cooper, EL, Engelmann, P, Bovari, J, Nemeth, P. Blurring borders: innate immunity with adaptive features. Clin. Dev. Immunol. 2007; 2007: 83671.

43. Lanier, LL, Sun, JC. Do the terms innate and adaptive immunity create conceptual barriers? Nat. Rev. Immunol. 2009; 9: 302-303.

44. Sun, JC, Lopez-Verges, S, Kim, CC, DeRisi, JL, Lanier, LL. NK Cells and Immune "Memory." J. Immunol. 2011; 186: 1891-1897.

45. Sun, JC, Ugolini, S, Vivier, E. Immunological memory within the innate immune system. EMBO J. 2014; 33: 1295-1303.

46. Cerwenka, A, Lanier, LL. Natural killer cell memory in infection, inflammation and cancer. Nat. Rev. Immunol. 2016; 16: 112.

47. O’Sullivan, TE, Sun, JC, Lanier, LL. Natural Killer Cell Memory. Immunity 2015; 43: $634-645$.

48. O'Leary, JG, Goodarzi, M, Drayton, DL, Andrian, UH von. T cell- and B cellindependent adaptive immunity mediated by natural killer cells. Nat. Immunol. 2006; 7: 507- 
516.

49. Paust, S, Gill, HS, Wang, B-Z, et al. Critical role for the chemokine receptor CXCR6 in NK cell-mediated antigen-specific memory of haptens and viruses. Nat. Immunol. 2010; 11: 1127-1135.

50. van den Boorn, JG, Jakobs, C, Hagen, C, et al. Inflammasome-Dependent Induction of Adaptive NK Cell Memory. Immunity 2016; 44: 1406-1421.

51. Reeves, RK, Li, H, Jost, S, et al. Antigen-specific NK cell memory in rhesus macaques. Nat. Immunol. 2015; 16: 927-932.

52. Lopez-Vergès, S, Milush, JM, Schwartz, BS, et al. Expansion of a unique $\mathrm{CD} 57^{+} \mathrm{NKG} 2 \mathrm{Chi}$ natural killer cell subset during acute human cytomegalovirus infection.

Proc. Natl. Acad. Sci. U. S. A. 2011; 108: 14725-14732.

53. Foley, B, Cooley, S, Verneris, MR, et al. Cytomegalovirus reactivation after allogeneic transplantation promotes a lasting increase in educated $\mathrm{NKG} 2 \mathrm{C}+$ natural killer cells with potent function. Blood 2012; 119: 2665-2674.

54. Cooper, MA, Elliott, JM, Keyel, PA, Yang, L, Carrero, JA, Yokoyama, WM. Cytokine-induced memory-like natural killer cells. Proc. Natl. Acad. Sci. U. S. A. 2009; 106: 1915-1919.

55. Cooper, MA, Yokoyama, WM. Memory-like responses of natural killer cells. Immunol. Rev. 2010; 235: 297-305.

56. Biswas, SK, Mantovani, A. Macrophage plasticity and interaction with lymphocyte subsets: cancer as a paradigm. Nat. Immunol. 2010; 11: 889.

57. Bowdish, DME, Loffredo, MS, Mukhopadhyay, S, Mantovani, A, Gordon, S. Macrophage receptors implicated in the "adaptive" form of innate immunity. Microbes Infect. 2007; 9: 1680-1687.

58. Foster, SL, Hargreaves, DC, Medzhitov, R. Gene-specific control of inflammation by TLR-induced chromatin modifications. Nature 2007; 447: 972-978.

59. Quintin, J, Saeed, S, Martens, JHA, et al. Candida albicans infection affords protection against reinfection via functional reprogramming of monocytes. Cell Host Microbe 2012; 12: 223-232.

60. Kaufmann, E, Sanz, J, Dunn, JL, et al. BCG Educates Hematopoietic Stem Cells to Generate Protective Innate Immunity against Tuberculosis. Cell 2018; 172: 176-190.e19.

61. Bekkering, S, Arts, RJW, Novakovic, B, et al. Metabolic Induction of Trained Immunity through the Mevalonate Pathway. Cell 2018; 172: 135-146.e9.

62. Song, WM, Colonna, M. Immune Training Unlocks Innate Potential. Cell 2018; 172: $3-5$.

63. Netea, MG, Joosten, LAB, Latz, E, et al. Trained immunity: A program of innate immune memory in health and disease. Science 2016; 352: aaf1098.

64. Martinez-Gonzalez, I, Mathä, L, Steer, CA, Takei, F. Immunological Memory of Group 2 Innate Lymphoid Cells. Trends Immunol. 2017; 38: 423-431.

65. Du Pasquier, L. \& Flajnik, M.F. (1999). Origin and evolution of the Vertebrate Immune system. Fundamental Immunology, 605-650.

66. Smith, LC, Hildemann, WH. Allograft rejection, autograft fusion and inflammatory responses to injury in Callyspongia diffusa (Porifera; Demospongia). Proc R Soc Lond B 1986; 226: 445-464.

67. Van de Vyver, G. (1980). Second set allograft rejection in two sponge species and the problem of an alloimmune memory. Phylogeny of Immunological Memory, 15-21.

68. Smith, LC, Hildemann, WH. Alloimmune memory is absent in Hymeniacidon sinapium, a marine sponge. J. Immunol. Baltim. Md 1950 1984; 133: 2351-2355.

69. Hildemann, WH, Raison, RL, Cheung, G, Hull, CJ, Akaka, L, Okamoto, J. Immunological specificity and memory in a scleractinian coral. Nature 1977; 270: 219. 
70. Theodor, JL. Distinction between "self" and "not-self" in lower invertebrates. Nature 1970; 227: 690-692.

71. Lubbock, R. Clone-specific cellular recognition in a sea anemone. Proc. Natl. Acad. Sci. 1980; 77: 6667-6669.

72. Langlet, C, Bierne, J. Immune characteristics of graft rejection in nemerteans of the genus Lineus. Eur. J. Immunol. 1982; 12: 705-708.

73. Cooper, EL, Roch, P. Second-set allograft responses in the earthworm Lumbricus terrestris. Kinetics and characteristics. Transplantation 1986; 41: 514-520.

74. Valembois, P. Recherches sur la nature de la réaction antigreffe chez le lombricien Eisenia foetida Savigny. Savigny C R Acad Sci Paris Sér D 1963; 3489-3492.

75. Duprat, T. Mise en évidence de reaction immunitaire dans les homogreffes de paroi du corps chez le lombricien Eisenia fetida typica. CR Acad Sci Paris Sér D 1964; 4177-4179. 76. Parry, MJ. Survival of body wall autographs, allografts, and xenografts in the earthworm Eisenia foetida. J. Invertebr. Pathol. 1978; 31: 383-388.

77. Hartman, RS, Karp, RD. Short-term immunologic memory in the allograft response of the American cockroach, Periplaneta americana. Transplantation 1989; 47: 920-922.

78. Dularay, B, Lackie, AM. The effect of biotic and abiotic implants on the recognition of Blatta orientalis cuticular transplants by the cockroach Periplaneta americana. Dev. Comp. Immunol. 1987; 11: 69-77.

79. Sullivan, JT, Galvan, AG, Lares, RR. Comparison of several types of allografts in Biomphalaria glabrata (Mollusca: Pulmonata). J. Invertebr. Pathol. 1998; 71: 1-8.

80. Karp, RD, Hildemann, WH. Specific allograft reactivity in the sea star Dermasterias imbricata. Transplantation 1976; 22: 434-439.

81. Coffaro, KA, Hinegardner, RT. Immune response in the sea urchin Lytechinus pictus. Science 1977; 197: 1389-1390.

82. Raftos, DA, Tait, NN, Briscoe, DA. Allograft rejection and alloimmune memory in the solitary urochordate, Styela plicata. Dev. Comp. Immunol. 1987; 11: 343-351.

83. Rinkevich, B, Weissman, IL. Incidents of rejection and indifference in $\mathrm{Fu} / \mathrm{HC}$ incompatible protochordate colonies. J. Exp. Zool. 1992; 263: 105-111.

84. Hildemann, WH, Thoenes, GH. Immunological Responses of Pacific Hagfish I. Skin Transplantation Immunity. Transplantation 1969; 7: 506.

85. Du Pasquier, L, Schwager, J, Flajnik, MF. The immune system of Xenopus. Annu. Rev. Immunol. 1989; 7: 251-275.

86. Pancer, Z, Amemiya, CT, Ehrhardt, GRA, Ceitlin, J, Gartland, GL, Cooper, MD. Somatic diversification of variable lymphocyte receptors in the agnathan sea lamprey. Nature 2004; 430: 174-180.

87. Chu, VT, Berek, C. The establishment of the plasma cell survival niche in the bone marrow. Immunol. Rev. 2013; 251: 177-188.

88. Hauton, C, Smith, VJ. Adaptive immunity in invertebrates: a straw house without a mechanistic foundation. BioEssays News Rev. Mol. Cell. Dev. Biol. 2007; 29: 1138-1146.

89. Little, TJ, Hultmark, D, Read, AF. Invertebrate immunity and the limits of mechanistic immunology. Nat. Immunol. 2005; 6: 651-654.

90. Little, TJ, Colegrave, N, Sadd, BM, Schmid-Hempel, P. Studying immunity at the whole organism level. BioEssays News Rev. Mol. Cell. Dev. Biol. 2008; 30: 404-405; author reply 406.

91. Coustau, C, Gourbal, B, Duval, D, Yoshino, TP, Adema, CM, Mitta, G. Advances in gastropod immunity from the study of the interaction between the snail Biomphalaria glabrata and its parasites: A review of research progress over the last decade. Fish Shellfish Immunol. 2015; 46: 5-16.

92. Yamaguchi, T, Quillet, E, Boudinot, P, Fischer, U. What could be the mechanisms 
of immunological memory in fish? Fish Shellfish Immunol. 2018;

93. Dooley, H, Flajnik, MF. Shark immunity bites back: affinity maturation and memory response in the nurse shark, Ginglymostoma cirratum. Eur. J. Immunol. 2005; 35: 936-945.

94. Wilson, M, Hsu, E, Marcuz, A, Courtet, M, Du Pasquier, L, Steinberg, C. What limits affinity maturation of antibodies in Xenopus--the rate of somatic mutation or the ability to select mutants? EMBO J. 1992; 11: 4337-4347.

95. Pham, LN, Dionne, MS, Shirasu-Hiza, M, Schneider, DS. A Specific Primed Immune Response in Drosophila Is Dependent on Phagocytes. PLOS Pathog. 2007; 3: e26.

96. Rodrigues, J, Brayner, FA, Alves, LC, Dixit, R, Barillas-Mury, C. Hemocyte Differentiation Mediates Innate Immune Memory in Anopheles gambiae Mosquitoes. Science 2010; 329: 1353-1355.

97. Saleh, M-C, Tassetto, M, Rij, RP van, et al. Antiviral immunity in Drosophila requires systemic RNA interference spread. Nature 2009; 458: 346-350.

98. Tassetto, M, Kunitomi, M, Andino, R. Circulating Immune Cells Mediate a Systemic RNAi-Based Adaptive Antiviral Response in Drosophila. Cell 2017; 169: 314325.e13.

99. West, C, Silverman, N. Drosophilosophical: Re-thinking Adaptive Immunity in the Fly. Cell 2017; 169: 188-190.

100. Armitage, SAO, Kurtz, J, Brites, D, Dong, Y, Du Pasquier, L, Wang, H-C. Dscam1 in Pancrustacean Immunity: Current Status and a Look to the Future. Front. Immunol. 2017; 8: 662 .

101. Milutinović, B, Peuß, R, Ferro, K, Kurtz, J. Immune priming in arthropods: an update focusing on the red flour beetle. Zoology 2016; 119: 254-261.

102. Conrath, U. Systemic Acquired Resistance. Plant Signal. Behav. 2006; 1: 179-184.

103. Chester, KS. The Problem of Acquired Physiological Immunity in Plants. Q. Rev. Biol. 1933; 8: 129-154.

104. Chester, KS. The Problem of Acquired Physiological Immunity in Plants (continued). Q. Rev. Biol. 1933; 8: 275-324.

105. Kuć, J. Induced Immunity to Plant Disease. BioScience 1982; 32: 854-860.

106. Jung, HW, Tschaplinski, TJ, Wang, L, Glazebrook, J, Greenberg, JT. Priming in systemic plant immunity. Science 2009; 324: 89-91.

107. Conrath, U, Beckers, GJM, Langenbach, CJG, Jaskiewicz, MR. Priming for enhanced defense. Annu. Rev. Phytopathol. 2015; 53: 97-119.

108. Durrant, WE, Dong, X. Systemic Acquired Resistance. Annu. Rev. Phytopathol. 2004; 42: 185-209.

109. Henry, E, Yadeta, KA, Coaker, G. Recognition of bacterial plant pathogens: local, systemic and transgenerational immunity. New Phytol. 2013; 199: 908-915.

110. Jaskiewicz, M, Conrath, U, Peterhänsel, C. Chromatin modification acts as a memory for systemic acquired resistance in the plant stress response. EMBO Rep. 2011; 12: $50-55$.

111. Datsenko, KA, Pougach, K, Tikhonov, A, Wanner, BL, Severinov, K, Semenova, E. Molecular memory of prior infections activates the CRISPR/Cas adaptive bacterial immunity system. Nat. Commun. 2012; 3: 945.

112. Fineran, PC, Charpentier, E. Memory of viral infections by CRISPR-Cas adaptive immune systems: Acquisition of new information. Virology 2012; 434: 202-209.

113. Heler, R, Marraffini, LA, Bikard, D. Adapting to new threats: the generation of memory by CRISPR-Cas immune systems. Mol. Microbiol. 2014; 93: 1-9.

114. Jackson, SA, McKenzie, RE, Fagerlund, RD, Kieper, SN, Fineran, PC, Brouns, SJJ. CRISPR-Cas: Adapting to change. Science 2017; 356: eaal5056.

115. Barrangou, R, Fremaux, C, Deveau, H, et al. CRISPR Provides Acquired 
Resistance Against Viruses in Prokaryotes. Science 2007; 315: 1709-1712.

116. Barrangou, R, Marraffini, LA. CRISPR-Cas systems: Prokaryotes upgrade to adaptive immunity. Mol. Cell 2014; 54: 234-244.

117. Janeway Jr., CA. The immune system evolved to discriminate infectious nonself from noninfectious self. Immunol. Today 1992; 13: 11-16.

118. Kuhn, TS. The structure of scientific revolutions. Chicago: University of Chicago Press, 1962.

119. Silverstein, AM. A history of immunology. 2nd eded. London ; Burlington, MA: Academic Press, 2009.

120. Richardson, RC. Autonomy and Multiple Realization. Philos. Sci. 2008; 75: 526536.

121. Bernasconi, NL, Onai, N, Lanzavecchia, A. A role for Toll-like receptors in acquired immunity: up-regulation of TLR9 by BCR triggering in naive B cells and constitutive expression in memory B cells. Blood 2003; 101: 4500-4504.

122. Sewell, AK. Why must T cells be cross-reactive? Nat. Rev. Immunol. 2012; 12 :

669-677.

123. Prescott, SL, Macaubas, C, Smallacombe, T, Holt, BJ, Sly, PD, Holt, PG.

Development of allergen-specific T-cell memory in atopic and normal children. The Lancet 1999; 353: 196-200.

124. Stacy, S, Krolick, KA, Infante, AJ, Kraig, E. Immunological memory and late onset autoimmunity. Mech. Ageing Dev. 2002; 123: 975-985.

125. Lakkis, FG, Sayegh, MH. Memory T Cells: A Hurdle to Immunologic Tolerance. J. Am. Soc. Nephrol. 2003; 14: 2402-2410.

126. Pradeu, T. The Limits of the Self: Immunology and Biological Identity. New York: Oxford University Press, 2012.

127. Pradeu, T. What is an organism? An immunological answer. Hist. Philos. Life Sci. 2010; 32: 247-268.

128. Benhamou, N, Nicole, M. Cell biology of plant immunization against microbial infection: The potential of induced resistance in controlling plant diseases. Plant Physiol.

Biochem. 1999; 37: 703-719.

129. Kothari, IL, Patel, M. Plant immunization. Indian J. Exp. Biol. 2004; 42: 244-252.

130. Barrangou, R, Klaenhammer, TR. Bacteria get vaccinated. Nature 2014; 513: 175.

131. Hynes, AP, Villion, M, Moineau, S. Adaptation in bacterial CRISPR-Cas immunity can be driven by defective phages. Nat. Commun. 2014; 5: 4399.

132. Mantovani, A. The chemokine system: redundancy for robust outputs. Immunol. Today 1999; 20: 254-257.

133. Mantovani, A. Redundancy and robustness versus division of labour and specialization in innate immunity. Semin. Immunol. 2017;

134. O'Leary, JG, Goodarzi, M, Drayton, DL, Andrian, UH von. T cell- and B cellindependent adaptive immunity mediated by natural killer cells. Nat. Immunol. 2006; 7: 507516.

135. Star, B, Nederbragt, AJ, Jentoft, S, et al. The genome sequence of Atlantic cod reveals a unique immune system. Nature 2011; 477: 207.

136. Sunyer, JO, Zarkadis, IK, Lambris, JD. Complement diversity: a mechanism for generating immune diversity? Immunol. Today 1998; 19: 519-523.

137. Norouzitallab, P, Baruah, K, Biswas, P, Vanrompay, D, Bossier, P. Probing the phenomenon of trained immunity in invertebrates during a transgenerational study, using brine shrimp Artemia as a model system. Sci. Rep. 2016; 6: 21166.

138. Robalino, J, Bartlett, T, Shepard, E, et al. Double-stranded RNA induces sequencespecific antiviral silencing in addition to nonspecific immunity in a marine shrimp: 
convergence of RNA interference and innate immunity in the invertebrate antiviral response? J. Virol. 2005; 79: 13561-13571.

139. Longdon, B, Cao, C, Martinez, J, Jiggins, FM. Previous Exposure to an RNA Virus Does Not Protect against Subsequent Infection in Drosophila melanogaster. PLOS ONE 2013; 8: e73833.

140. McTaggart, SJ, Wilson, PJ, Little, TJ. Daphnia magna shows reduced infection upon secondary exposure to a pathogen. Biol Lett 2012; 8: 972-975.

141. Duneau, D, Ebert, D, Du Pasquier, L. Infections by Pasteuria do not protect its natural host Daphnia magna from subsequent infections. Dev. Comp. Immunol. 2016; 57: 120-125. 142. Goic, B. \& Saleh, M.-C. (2010). RNAi: An Antiviral Defense System in Insects. RNA Interference and Viruses: Current Innovations and Future Trends, 1-24.

143. Weavers, H, Evans, IR, Martin, P, Wood, W. Corpse Engulfment Generates a Molecular Memory that Primes the Macrophage Inflammatory Response. Cell 2016; 165: 1658-1671. 144. Adema, CM. Fibrinogen-Related Proteins (FREPs) in Mollusks. Results Probl Cell Differ 2015; 57: 111-129.

145. Wang, M, Wang, L, Xin, L, et al. Two novel LRR-only proteins in Chlamys farreri: Similar in structure, yet different in expression profile and pattern recognition. Dev. Comp. Immunol. 2016; 59: 99-109.

146. Rauta, PR, Samanta, M, Dash, HR, Nayak, B, Das, S. Toll-like receptors (TLRs) in aquatic animals: signaling pathways, expressions and immune responses. Immunol. Lett. 2014; 158: 14-24.

147. Satake, H, Sekiguchi, T. Toll-Like Receptors of Deuterostome Invertebrates. Front Immunol 2012; 3:

148. Dishaw, LJ, Leigh, B, Cannon, JP, et al. Gut immunity in a protochordate involves a secreted immunoglobulin-type mediator binding host chitin and bacteria. Nature Communications 2016; 7: 10617. 